\title{
INFLUÊNCIA DE DIFERENTES SUBSTRATOS NA PRODUÇÃO DE FITOCONSTITUINTES DE Moringa oleifera Lam. CULTIVADA A PLENO SOL
}

\section{INFLUENCE OF DIFFERENT SUBSTRATES ON THE PRODUCTION OF PHYTOCONSTITUENTS OF Moringa oleifera Lam. GROWN IN FULL SUN}

\author{
José Carlos Pina ${ }^{1}$ Ademir Kleber Morbeck de Oliveira ${ }^{2}$ Rosemary Matias ${ }^{3}$ Fernanda da Silva ${ }^{4}$
}

\begin{abstract}
RESUMO
A análise de extratos de folhas de Moringa oleifera cultivadas em diferentes substratos oferece a oportunidade de se examinar um conjunto de metabólitos secundários, que podem ser utilizados para diversos fins, como nutrientes e na medicina. Levando-se esses fatores em consideração, foi montado um experimento em delineamento experimental, conduzido com blocos inteiramente casualizados, com sete tratamentos: (1) 100\% neossolo quartzarênico; (2) neossolo quartzarênico $60 \%$ x $40 \%$ vermicomposto; (3) neossolo quartzarênico $80 \%$ x 20\% vermicomposto; (4) neossolo quartzarênico $60 \%$ x $40 \%$ casca de arroz carbonizada; (5) neossolo quartzarênico $80 \%$ x $20 \%$ casca de arroz carbonizada; (6) neossolo quartzarênico $60 \%$ x 40\% solo argiloso; e, (7) neossolo quartzarênico $40 \%$ x $60 \%$ solo argiloso, a pleno sol, quatro repetições por tratamento. A avaliação de crescimento da parte aérea foi realizada aos 105 dias, com a coleta das folhas, secas em estufa de ventilação forçada e posteriormente trituradas e pesadas. Com o material obtido foram preparados extratos metanólicos e aquosos $(20 \%)$, submetidos à análise fitoquímica. Foi detectada a presença de compostos fenólicos, taninos, flavonoides, cumarinas, esteroides, heterosídeos cardioativos, alcaloides e açúcares redutores. Estes compostos são provavelmente os responsáveis em conferir amplo espectro de atividades biológicas atribuídas às folhas da espécie. Porém, o presente estudo sugere cautela em seu uso indiscriminado, devido à grande presença de heterosídeos cardioativos. A maior ou menor quantidade de metabólitos foi influenciada pelos diferentes substratos e, na dependência do tipo de utilização da espécie diferentes tipos de cultivos seriam necessários para aumentar ou diminuir determinados compostos presentes em suas folhas.
\end{abstract}

Palavras-chave: metabólitos secundários; análise de crescimento; Moringaceae.

\begin{abstract}
The analysis of Moringa oleifera leaf extracts when grown on different substrates provides the opportunity to examine a set of secondary metabolites, which can be utilized for various purposes, as nutrients and in medicine. Taking those factors into consideration, an experiment was set up in a completely randomized block, conducted with seven treatments: (1) $100 \%$ quartzipsamment; (2) quartzipsamment $60 \%$ x $40 \%$ vermicompost; (3) quartzipsamment $80 \%$ x $20 \%$ vermicompost; (4) quartzipsamment $60 \%$ x $40 \%$ carbonized rice husk; (5) quartzipsamment $80 \%$ x $20 \%$ carbonized rice husk; (6) quartzipsamment $60 \%$ x $40 \%$ clay soil; and (7) quartzipsamment $40 \%$ x 60\% clay soil, in full sun, with four replicates per treatment. The

1 Gestor Ambiental, MSc., Doutorando em Meio Ambiente e Desenvolvimento Regional, Universidade Anhanguera - Uniderp, Rua Alexandre Herculano, 1400, Bairro Jardim Veraneio, CEP 79037-280, Campo Grande (MS), Brasil. josecarlospina@gmail.com

2 Biológo, Dr., Professor do Programa de Pós-Graduação em Meio Ambiente e Desenvolvimento Regional, Universidade Anhanguera - Uniderp, Rua Alexandre Herculano, 1400, Bairro Jardim Veraneio, CEP 79037-280, Campo Grande (MS), Brasil. akmorbeckoliveira@gmail.com

3 Química, Dra.., Professora do Programa de Pós-Graduação em Meio Ambiente e Desenvolvimento Regional, Universidade Anhanguera - Uniderp, Rua Alexandre Herculano, 1400, Bairro Jardim Veraneio, CEP 79037-280, Campo Grande (MS), Brasil. rosematiasc@gmail.com

4 Acadêmico do Curso de Farmácia, Universidade Anhanguera - Uniderp, Rua Alexandre Herculano, 1400, Bairro Jardim Veraneio, CEP 79037-280, Campo Grande (MS), Brasil. silva.fernandad@gmail.com
\end{abstract}

Recebido para publicação em 15/06/2016 e aceito em 28/07/2017

Ci. Fl., v. 28, n. 3, jul. - set., 2018 
shoot growth evaluation was performed at 105 days, with the leaves collected, dried in a forced ventilation oven and later crushed and weighed. With the material obtained, methanolic and aqueous extracts were prepared at $20 \%$ and submitted to phytochemical analysis. The presence of phenolic compounds, tannins, flavonoids, coumarins, steroids, cardioactive heterosides, alkaloids and reducing sugars was detected. These compounds are probably responsible for conferring a broad spectrum of biological activities attributed to the leaves of the species. However, the present study suggests caution in its indiscriminate use due to the great presence of cardioactive heterosides. The greater or lesser amount of metabolites was influenced by the different substrates and, depending on the type of use of the species, different types of crops would be necessary to increase or decrease certain compounds present in its leaves.

Keywords: secondary metabolites; growth analysis; Moringaceae.

\section{INTRODUÇÃO}

A espécie arbórea Moringa oleifera Lam. (Moringaceae) tem como local de origem o norte da Índia, possuindo folhas perenes e sendo de crescimento rápido ( 1 a $2 \mathrm{~m}$ por ano), atingindo até $12 \mathrm{~m}$ de altura nos primeiros 3 a 4 anos. Propaga-se por sementes e estacas, com bom poder de rebrota e não necessita de muitos cuidados, sobrevivendo a longos períodos de seca. Pode ser cultivada em solo com estrutura argilosa média ou arenosa e com acidez moderada, considerados os melhores para a espécie, devido a sua boa drenagem; porém, não cresce adequadamente em condições alagadas (PARROTTA, 2009; PHIRI; MBEWE, 2010).

Por tratar-se de uma planta de uso diversificado, especialmente pelo seu valor nutricional, foi introduzida em várias regiões tropicais. No Brasil, seu cultivo, na década de 1950, ocorreu como planta ornamental e medicinal, adaptando-se às regiões do Cerrado e Semiárido. Suas folhas têm potencial de uso industrial, medicinal e na alimentação (SANTANA et al., 2010; SILVA JUNIOR, 2013). De acordo com Anwar et al. (2007), a farinha das suas folhas é utilizada como fonte alternativa de nutrientes no combate à desnutrição.

As folhas são ricas em vitaminas, proteínas, aminoácidos essenciais, $\alpha$ - e $\gamma$-tocoferóis e $\beta$-caroteno, o que justifica seu uso na alimentação. Por outro lado, a presença dos compostos fenólicos, flavonoides, óleos essenciais e glicosídeos livres, flavônicos e terpênicos, indicam seu potencial medicinal (FAHEY, 2005; CHUANG et al., 2007; TORRES-CASTILLO et al., 2013). O uso medicinal de Moringa oleifera está relacionado com suas propriedades analgésicas, anti-inflamatórias, antipiréticas, antitumorais, antiespasmódicas, antioxidantes, antiúlceras, diuréticas e hepatoprotetoras, além de atuar na redução da hipertensão arterial e do colesterol, entre outras ações (ANWAR et al., 2007).

Contudo, o cultivo de espécies de interesse em diferentes regiões, sob diversas condições ambientais, pode influenciar na composição e concentração dos fitoquímicos produzidos. De acordo com Costa et al. (2008) e Taiz e Zeiger (2013), o substrato pode exercer grande influência na produção de metabólitos secundários. No entanto, o estudo da composição fitoquímica de estruturas vegetativas de Moringa oleifera, quando cultivada em diferentes substratos, ainda não foi realizado. Como a espécie possui interesse regional por sua capacidade de adaptar-se a climas tropicais e a quase todo tipo de solo, sendo atrativa por ser de fácil cultivo, com baixo custo de produção e alto rendimento (RODRIGUES et al., 2016), objetivou-se com este trabalho investigar o crescimento e composição fitoquímica de folhas de Moringa oleifera após 105 dias de desenvolvimento em diferentes substratos, a pleno sol.

\section{MATERIAL E MÉTODO}

\section{Material}

O experimento foi conduzido na Universidade Anhanguera-Uniderp, Unidade Agrárias, localizada na Latitude $20^{\circ} 26^{\prime} 16,6^{\prime \prime} \mathrm{S}$ e, Longitude 5432'14,5" O, Campo Grande, Mato Grosso do Sul, entre o período de janeiro a abril de 2014. Com altitude de $665 \mathrm{~m}$, o clima da região, segundo a classificação de Köppen-Geiger, situa-se na faixa de transição entre o subtipo (Cfa) mesotérmico úmido sem estiagem ou pequena estiagem e o subtipo (Aw) tropical úmido, com estação chuvosa e quente no verão e seca 
no inverno; a precipitação pluviométrica média anual é de $1.430 \mathrm{~mm}$ e temperatura média anual, $23^{\circ} \mathrm{C}$ (INSTITUTO NACIONAL DE PESQUISAS ESPACIAIS, 2014).

\section{Substrato}

O solo utilizado como base para todos os tratamentos é do tipo neossolo quartzarênico órtico, coletado no campus da universidade; o solo argiloso, na Fazenda Escola Três Barras, pertencente também à universidade. Os solos foram retirados de uma profundidade de $0-20 \mathrm{~cm}$, secos sobre lona a pleno sol, peneirados e então analisados de acordo com Donagema et al. (2011) para os atributos, $\mathrm{pH}$ em $\mathrm{H}_{2} \mathrm{O}$, $\mathrm{P}$ e K, método de Mehlich-1, $\mathrm{Ca}, \mathrm{Mg}$ e $\mathrm{Al}+\mathrm{H}$, método $\mathrm{KCl}(1 \mathrm{~N})$, matéria orgânica, método colorimétrico e, argila, silte e areia, método da pipeta (CLAESSEN, 1997) (Tabela 1).

Os substratos vermicomposto (VC) e casca de arroz carbonizada (CAC) foram analisados conforme Tedesco et al. (1995), para os atributos $\mathrm{pH}$ em $\mathrm{H}_{2} \mathrm{O}, \mathrm{P}, \mathrm{K}, \mathrm{Ca}, \mathrm{Mg}, \mathrm{Al}+\mathrm{H}$ e matéria orgânica (Tabela 1). A casca de arroz carbonizada foi preparada através do sistema de carbonização (KÄMPF, 2005) e o vermicomposto, com resíduos de rúmen de bovinos, compostado por 30 dias através de minhocas vermelhada-califórnia (Eisenia foetida) e mantido na sombra por 70 dias, antes do uso.

TABELA 1: Análise dos principais componentes químicos e físicos dos substratos utilizados $(\mathrm{NQ}=$ neossolo quartzarênico; $\mathrm{VC}=$ vermicomposto; $\mathrm{CAC}=$ casca de arroz carbonizada; $\mathrm{SA}=$ solo argiloso).

TABLE 1: $\quad$ Analysis of the main chemical and physical components of the substrates used (NQ = quartzipsamment; $\mathrm{VC}=$ vermicompost $\mathrm{CAC}=$ carbonized rice husk; $\mathrm{SA}=$ clay soil $)$.

\begin{tabular}{c|cccccc|cccc}
\hline Substratos & \multicolumn{7}{|c|}{ Íons } & \multicolumn{4}{c}{ Granulometria } \\
\cline { 2 - 10 } & $\mathrm{pH}$ & $\mathrm{P}$ & $\mathrm{K}^{+}$ & $\mathrm{Ca}^{+2}$ & $\mathrm{Mg}^{+2}$ & $\mathrm{H}^{+}+\mathrm{Al}^{3+}$ & $\mathrm{MO}$ & Argila & Silte & Areia \\
\hline $\mathrm{NQ}$ & 6,1 & 1,5 & 12 & 2,4 & 1,2 & 2,7 & 20,1 & 120 & 40 & 840 \\
$\mathrm{VC}$ & 7 & 260 & 460 & 25 & 22 & 65 & 18,6 & - & - & - \\
$\mathrm{CAC}$ & 6 & 1,8 & 2,7 & 2,8 & 0,6 & 6,5 & 22,9 & - & - & - \\
$\mathrm{SA}$ & 5,8 & 8 & 75 & 3,2 & 1,2 & 4,8 & 32,2 & 514 & 52 & 434 \\
\hline
\end{tabular}

Em que: $\mathrm{pH}=\mathrm{pH}$ em $\mathrm{H}_{2} \mathrm{O}(1: 25) ; \mathrm{P}=$ fósforo $\left(\right.$ Mehlich-1 mg/dm $\left.{ }^{3}\right) ; \mathrm{K}=$ potássio $\left(\right.$ Mehlich-1 mg/dm $\left.{ }^{3}\right) ; \mathrm{C}=\mathrm{cálcio}$ (extração $\mathrm{KCl}) ; \mathrm{Mg}=$ magnésio; $\mathrm{H}^{+}+\mathrm{Al}^{3+}=$ hidrogênio + alumínio; $\mathrm{Al}=$ alumínio $\left(\mathrm{cmol}_{\mathrm{c}} / \mathrm{dm}^{3}\right) ; \mathrm{MO}=$ matéria orgânica $\left(\mathrm{g} / \mathrm{dm}^{3}\right)$; granulometria $=(\mathrm{g} / \mathrm{kg})$.

De acordo com as proporções estipuladas para cada tratamento, foram realizadas as misturas dos componentes e, após a homogeneização, os substratos foram acondicionados em sacos plásticos de plantio (20 cm de largura x $30 \mathrm{~cm}$ altura) com capacidade volumétrica de $3,41\left(3,4 \mathrm{dm}^{3}\right)$.

Os tratamentos montados foram: T1) neossolo quartzarênico 100\%; T2) neossolo quartzarênico $60 \%$ x 40\% vermicomposto; T3) neossolo quartzarênico $80 \%$ x $20 \%$ vermicomposto; T4) neossolo quartzarênico $60 \%$ x 40\% casca de arroz carbonizada; T5) neossolo quartzarênico $80 \%$ x 20\% casca de arroz carbonizada; T6) neossolo quartzarênico $60 \%$ x $40 \%$ solo argiloso; e, T7) neossolo quartzarênico $40 \%$ x $60 \%$ solo argiloso.

\section{Coleta de sementes}

As sementes de Moringa oleifera foram provenientes de 12 matrizes cultivadas na região da Nhecolândia, Pantanal Sul-Mato-Grossense. Após coleta, foram transportadas para o Laboratório de Pesquisa em Sistemas Ambientais e Biodiversidade, Universidade Anhanguera-Uniderp e colocadas para germinar em bandejas de poliestireno expandido de 128 células contendo vermiculita; quando as plântulas atingiram $4 \mathrm{~cm}$ acima do substrato (limite observado do estiolamento), foram transplantadas para os sacos de cultivo contendo os diferentes substratos, uma plântula por recipiente. Após dois dias de aclimatação, na sombra, os recipientes foram transferidos para campo e mantidos a pleno sol, com a média da radiação máxima 
diária de 2797,5 $\mathrm{KJ} \mathrm{m}^{2}$, no período de janeiro a abril de 2014, com dados obtidos na Estação Meteorológica Campo Grande-A702 (INSTITUTO NACIONAL DE METEOROLOGIA, 2014), observando-se o pico máximo diário dos 105 dias de duração do experimento e calculando-se a média ao final.

Avaliação de crescimento e massa seca foliar

Decorridos 105 dias após o transplantio (DAT), a altura das mudas foi mensurada através de régua graduada, medindo-se do colo da plântula até o ápice da parte aérea $(\mathrm{cm})$. Em sequência, as folhas foram coletadas, acondicionadas em sacos de papel e colocadas em estufa de ventilação forçada a $40-50^{\circ} \mathrm{C}$ durante 48 horas e após este período foi determinado o peso seco em balança analítica ( $\pm 0,0001 \mathrm{~g})$. Posteriormente, foram trituradas em moinho elétrico e o pó resultante armazenado em frasco de vidro âmbar hermeticamente fechado, rotulado e guardado em geladeira, até a preparação dos extratos.

\section{Obtenção dos extratos}

O extrato metanólico a $20 \%$ foi obtido através do uso de $20 \mathrm{~g}$ do pó das folhas secas dos tratamentos (T1 a T7) por $100 \mathrm{~mL}$ de metanol 99,5\%. Inicialmente, os extratos foram submetidos à extração em aparelho de ultrassom (UNIDQUE ${ }^{\circledR}, 1450$ ) por 60 minutos, seguindo-se por 48 horas de extração por maceração estática (OLIVEIRA et al., 2013); posteriormente, foram filtrados em papel de filtro, utilizando-se funil de vidro. Para confirmação da presença de algumas classes de metabólitos secundários, determinados testes foram repetidos com o extrato aquoso, obtido por decocção de $2,0 \mathrm{~g}$ do pó de folhas e $10,0 \mathrm{~mL}$ de água destilada por 3 minutos.

\section{Análise fitoquímica}

Os extratos obtidos foram submetidos à prospecção fitoquímica, seguindo metodologia de Matos (2009); para confirmação das classes de metabólitos secundários, foi utilizado procedimento de Wagner e Bladt (2009). As análises de caracterização foram de compostos fenólicos (reação de precipitação com cloreto férrico), naftoquinona (reação ácido/base), flavonoides (reação de cianidina e ácido sulfúrico), taninos (reação com sais de ferro, precipitação de proteínas), cumarinas ( $\mathrm{KOH} / \mathrm{luz}$ ultravioleta), triterpenos e esteroides (reação de Liebermann-Burchard), heterosídeos cianogênicos (teste de Guignard), heterosídeos cardioativos (teste de Baljet e de Kedde), saponinas (reação de Lieberman-Burchard) e açúcares redutores (reação de Benedict).

As análises foram executadas em triplicatas e os resultados, comparados e contrastados, observandose a alteração de cor e precipitação com o extrato original. Para determinar a presença das classes de metabólitos secundários nos diferentes tratamentos, as intensidades das reações de caracterização foram classificadas como: 0 (zero) para reação negativa, intensidade parcial $( \pm /+=10 \%)$, baixa $(++=50 \%)$, média $( \pm++=75 \%)$ e alta intensidade $(+++=100 \%)$, calculando-se a média ao final (FONTOURA et al., 2015).

Para confirmar a presença ou ausência de saponinas foi empregado o teste de ação superficial adaptado de Athayde et al. (2017) e o ensaio realizado com o extrato aquoso e metanólico. Após agitação enérgica do extrato filtrado em tubo de ensaio, seguido de repouso por 15 minutos, foi observada a formação de espuma, que no caso do teste positivo não desaparece com a adição de ácido. A altura da espuma foi medida e a leitura feita com base em Fontoura et al. (2015).

A confirmação da presença de heterosídeos cardioativos ocorreu nos extratos metanólico e aquoso dos sete tratamentos, empregando-se os ensaios: reação de Liebermann-Burchard (reação do núcleo esteroidal), reação de Keller-Killiani e de Pesez (desoxiaçúcares) e reação de Baljet e de Kedde (anel lactônico). Já para a confirmação da presença dos triterpenos e esteroides realizou-se a hidrólise do extrato metanólico seco, com hidróxido de potássio $(0,5 \mathrm{M})$, submetido a refluxo por 1 hora. Os extratos foram extraídos com éter etílico e em sequência submetidos à reação de Liebermann-Burchard.

A quantificação dos fenóis totais (FT) foi feita pelo Método Folin-Ciocalteu; a equação de regressão de calibração $\left(\mathrm{y}=0,781 \mathrm{x}-0,0031 ; \mathrm{R}^{2}=0,996\right)$ foi construída com padrão de ácido gálico $(10$ a $350 \mathrm{mg}$ $\mathrm{mL}^{-1}$ ) (SOUSA et al., 2007). Os flavonoides (F) foram quantificados pelo método do cloreto de alumínio 
(PEIXOTO SOBRINHO et al., 2008) e como padrão, a quercetina $(0,04 ; 0,2 ; 0,4 ; 2 ; 4 ; 8 ; 12 ; 16$ e $20 \mathrm{mg}$ $\left.\mathrm{mL}^{-1}\right)$, utilizada para construir a curva de calibração $\left(\mathrm{y}=0,0633 \mathrm{x}-0,0061 ; \mathrm{R}^{2}=0,999\right)$.

\section{Delineamento experimental}

O delineamento foi realizado em blocos inteiramente casualizados ( 7 substratos x 1 época de coleta), sendo utilizadas quatro plantas por tratamento. Os dados de quantificação de compostos fenólicos e flavonoides, massa seca foliar e crescimento em altura foram submetidos à análise de variância e quando houve significância, foi aplicado o teste de médias de Tukey a 5\% de probabilidade.

\section{RESULTADOS E DISCUSSÃO}

As análises fitoquímicas indicaram a presença de compostos fenólicos, taninos, flavonoides, cumarinas, heterosídeos cardioativos, esteroides e açúcares redutores em todos os tratamentos avaliados, em diferentes quantidades; já os alcaloides foram detectados apenas nos substratos contendo vermicomposto (T2 e T3), em baixa intensidade (Tabela 2). Por outro lado, antraquinonas, antocianinas, heterosídeos cianogênicos, saponinas e triterpenos, nos extratos metanólico e aquoso, não foram detectados.

TABELA 2: Análise fitoquímica de folhas de Moringa oleifera, aos 105 dias de plantio a pleno sol, Campo Grande, Mato Grosso do Sul.

TABLE 2: Phytochemical analysis of leaves from Moringa oleifera at 105 days of cultivation in full sun, Campo Grande, Mato Grosso do Sul.

\begin{tabular}{|c|c|c|c|c|c|c|c|c|}
\hline \multirow{2}{*}{$\begin{array}{l}\text { Metabólitos } \\
\text { Secundários }\end{array}$} & \multicolumn{8}{|c|}{ Tratamentos } \\
\hline & $\mathrm{T} 1$ & $\mathrm{~T} 2$ & $\mathrm{~T} 3$ & $\mathrm{~T} 4$ & $\mathrm{~T} 5$ & T6 & $\mathrm{T} 7$ & Int $\%$ \\
\hline $\begin{array}{l}\text { Compostos } \\
\text { fenólicos }\end{array}$ & + & ++ & ++ & +++ & + & +++ & +++ & 64,3 \\
\hline Taninos & ++ & ++ & ++ & ++ & ++ & + & + & 42,9 \\
\hline Flavonoides & \pm & ++ & ++ & + & + & ++ & \pm & 35,7 \\
\hline Cumarinas & + & + & + & + & + & + & + & 25 \\
\hline Esteroides & + & ++ & + & ++ & + & ++ & + & 35,7 \\
\hline $\begin{array}{l}\text { Heterosídeos } \\
\text { cardioativos }\end{array}$ & +++ & ++ & +++ & +++ & +++ & + & + & 71,4 \\
\hline Alcaloides & - & + & + & - & - & - & - & 7,1 \\
\hline $\begin{array}{l}\text { Açúcares } \\
\text { redutores }\end{array}$ & + & + & + & + & + & + & + & 35,7 \\
\hline Teor CF & $162 \pm .3 f$ & $161 \pm .2 \mathrm{~g}$ & $169 \pm .3 \mathrm{~d}$ & $173 \pm .1 b$ & $164 \pm .2 \mathrm{e}$ & $177 \pm .5 \mathrm{a}$ & $171 \pm .4 \mathrm{c}$ & --- \\
\hline Teor F & $2,4 \pm 1,0 \mathrm{~g}$ & $143 \pm 1,9 \mathrm{c}$ & $166 \pm .6 \mathrm{a}$ & $91 \pm .4 \mathrm{~d}$ & $85 \pm 1,5 \mathrm{e}$ & $151 \pm .6 \mathrm{~b}$ & $12 \pm 1,7 \mathrm{f}$ & --- \\
\hline
\end{tabular}

Em que: $\mathrm{T} 1=$ controle $(\mathrm{NQ} 100) ; \mathrm{T} 2=\mathrm{NQ} 60 \times 40 \mathrm{VC}$; T3 = NQ80 x 20VC; T4 = NQ60 x 40CAC; T5 = NQ80 x 20CAC; T6 = NQ60 x 40SA; T7 = NQ40 x 60SA. NQ = neossolo quartzarênico; VC = vermicomposto; CAC $=$ casca de arroz carbonizada; $\mathrm{SA}=$ solo argiloso; Int = Intensidade; negativa (-); intensidade parcial $( \pm /+=25 \%)$, baixa $(++=$ $50 \%)$, média $( \pm++=75 \%)$ e alta intensidade $(+++=100 \%) . \mathrm{CF}=$ Compostos fenólicos; $\mathrm{F}=$ Flavonoides. 
De acordo com Gobbo Neto e Lopes (2007), Morais (2009) e Pegoraro et al. (2010), a produção de metabólitos secundários pela planta ocorre em função da interação planta versus ambiente, em resposta a fatores abióticos (fatores climáticos, tais como temperatura, intensidade de luz, substrato e sazonalidade) e bióticos (interações planta/microrganismos, planta/insetos e planta/planta; idade, estádio de desenvolvimento e genética). Esta interação pode explicar a diversidade, a quantidade e/ou a ausência dos metabólitos secundários nos extratos de uma mesma espécie cultivada em diferentes substratos, indicando que o maior acúmulo de massa seca e crescimento pode não significar maior produção de metabólitos. Por outro lado, muitos aleloquímicos representam caracteres adaptativos da espécie e têm se diversificado durante a evolução pela seleção natural, a fim de proteger a planta contra fatores bióticos e abióticos (CARDOSO et al., 2001; WINK, 2003; GOBBO-NETO; LOPES, 2007).

$\mathrm{Na}$ análise qualitativa, a maior diversidade de metabólitos secundários foi evidenciada nos tratamentos T2 e T3 (oito classes), seguidos dos demais tratamentos com sete classes. Em relação à intensidade das reações de caracterização, dentre as classes analisadas, os compostos fenólicos $(64,3 \%)$ e os heterosídeos cardioativos $(71,4 \%)$ apresentaram maior intensidade $(+++)$, indicando serem estes os representantes majoritários para a espécie, nos substratos utilizados (Tabela 2).

Porém, os resultados negativos para a presença de determinados metabólitos não implicam necessariamente em sua ausência; isto ocorre porque a quantidade dos mesmos, quando em escala inferior a semimicro, muitas vezes não é detectada na análise qualitativa (HARBORNE, 1998). Em muitos casos, o solvente extrator também pode ter influência na extração dos fitoconstituintes. Conforme Ayinde, Onwukaeme e Omogbai (2007) e Tijani et al. (2009), nem todos os fitoquímicos estão presentes em todas as partes da planta e aqueles presentes diferem, de acordo com o método de extração e a polaridade do solvente.

Os tratamentos T4, T6 e T7 apresentaram alta intensidade de compostos fenólicos na análise qualitativa, que foi confirmada pela alta concentração na determinação quantitativa, seguido do tratamento T3. A maior intensidade/concentração destes compostos foi observada quando da presença da argila (T6 e T7) e maior quantidade de casca de arroz (T4) na composição dos substratos (Tabela 2).

Neste caso, deve-se considerar qual tipo de solo é adaptado ao plantio da espécie Moringa oleifera, levando-se em consideração os objetivos do cultivo. Segundo Dubey et al. (2013), esta espécie desenvolvese melhor em solos neutros para ligeiramente ácidos, bem drenados e com textura argilosa média. Já Foidl, Mayorga e Vásquez (2003) apontam que ela se adapta a diversas classes de solos, exceto aos mal drenados, o que pode ter causado algum estresse à planta nos tratamentos T6 e T7 (argilosos), o que justifica a maior intensidade de compostos fenólicos para algumas amostras. De acordo com Gobbo-Neto e Lopes (2007), Morais (2009) e Pegoraro et al. (2010), o estresse ambiental pode alterar a produção de determinados tipos de metabólitos pelas plantas, e o estresse hídrico tem consequências significativas nas concentrações de metabólitos secundários, podendo diminuir a sua produção.

De acordo com Capeche et al. (2004), os solos argilosos são considerados solos pesados (com mais de $40 \%$ de argila pura) por possuírem uma quantidade maior de microporos, o que pode dificultar a infiltração da água. Para Morelli (2010), estes solos, por terem alta capacidade de retenção de água e tendência de ficarem compactados ao longo do tempo, dificultam o desenvolvimento das raízes.

Os flavonoides e compostos fenólicos apresentaram um perfil semelhante nas análises qualitativas, sendo encontrados em distintas intensidades nos diferentes extratos em análise. Entretanto, pode-se identificar que a presença de vermicomposto nos substratos proporcionou uma maior intensidade de flavonoides, similar ao ocorrido no substrato com argila em menor quantidade (T2, T3 e T6), com intensidade e frequência média $(35,7 \%)$. A avaliação quantitativa também indicou serem estes os tratamentos com os maiores teores (Tabela 2).

Estes dados indicam que os tratamentos interferiram na intensidade das reações para os compostos encontrados nas folhas, principalmente os fenólicos e seus derivados. No caso dos flavonoides, estes atuam na proteção contra a fotodestruição, absorvendo e/ou dissipando a energia solar, dificultando, assim, danos aos tecidos mais internos pela radiação UV-B, sem alterar a radiação fotossinteticamente ativa que chega aos cloroplastos (GOBBO-NETO; LOPES, 2007), além de possuir propriedades antioxidantes, antiinflamatórias e antimicrobianas, dentre outras (ZUANAZZI; MONTANHA, 2010). Para a espécie em estudo, a presença de flavonoides é correlacionada à atividade antimicrobiana, potencial hipoglicemiante 
(ANWAR et al., 2007) e antitumoral (WILLIAMS et al., 2004). Logo, para fins medicinais, sugere-se o uso dos substratos dos tratamentos T2, T3 e T6 para maior produção de compostos fenólicos e flavonoides; também se deve levar em consideração que T2 e T3 apresentaram médias e altas intensidades de heterosídeos cardioativos.

Contudo, a intensidade na presença de compostos fenólicos e flavonoides não apresentou um padrão claro e, outro fator, tal como diferenças de luminosidade, seria um dos indicadores necessários para a obtenção de maiores valores ou um padrão claro de qual é o melhor tratamento para a produção de ambos. De acordo com Gobbo-Neto e Lopes (2007) e Taiz e Zeiger (2013), além do substrato, existe uma correlação positiva bem estabelecida entre intensidade de radiação solar e produção de compostos fenólicos, como flavonoides e taninos. Segundo Mariot e Barbieri (2007), a concentração de polifenóis totais em plantas que se encontram em pleno sol é maior, indicando que a luminosidade é um dos fatores abióticos que influenciam a produção destes compostos. Pegoraro et al. (2010) também verificaram que a composição química dos metabólitos varia conforme a intensidade luminosa em plantas de Mentha, indicando a importância deste fator ambiental.

Outro grupo de polifenóis, os taninos, apresentaram nos tratamentos T6 e T7 baixa intensidade, enquanto T1, T2, T3, T4 e T5, média intensidade (++), 42,9\%. A presença de taninos de intensidade média na maior parte dos diferentes tratamentos (exceto nos contendo argila) difere dos resultados encontrados por Bamishaiye et al. (2011), que não detectaram esta classe de metabólito secundário em extrato metanólico de folhas de moringa. Já Kasolo et al. (2011) encontraram vestígios de taninos nas folhas da espécie, quando cultivada em Uganda, África. Resultados similares foram citados por Melo (2012), apontando quantidades pouco significativas de taninos $(1,4 \%)$ e saponinas $(5 \%)$. Os resultados obtidos por este experimento demonstraram que esta classe de metabólito pode ocorrer em maior intensidade, na dependência do tipo de cultivo. Apenas os tratamentos com presença de solo argiloso (T6 e T7) apresentaram intensidade baixa, enquanto os demais, média. Então, quase todos os tratamentos seriam adequados para a produção de taninos em cultivos de Moringa oleifera para fins medicinais, por suas propriedades adstringentes, antidiarreicas, antissépticas e cicatrizantes, dentre outras (ANWAR et al., 2007).

Como afirmado por Capeche et al. (2004) e Morelli (2010), solos argilosos podem dificultar a infiltração da água e/ou ter alta capacidade de retenção de água, podendo levar ao estresse hídrico e ambiental, o que pode ter levado a uma menor produção de taninos.

Desta maneira, o possível estresse causado pela maior presença de argila, dificultando o crescimento das raízes, foi mais favorável à produção dos fenóis totais. Para o tratamento T4, o maior teor de fenóis também deve estar relacionado ao estresse, uma vez que a casca de arroz carbonizada na composição do substrato (40\%) possui baixo teor de nutrientes, além de ocasionar uma drenagem rápida de água; o substrato T5 também possui CAC (20\%) em sua composição. A presença deste composto provavelmente foi a responsável pela maior drenagem dos substratos e, consequentemente, maior restrição hídrica. De acordo com Saidelles et al. (2009), este resíduo é um material pobre em nutrientes (exceto K e Ca) e apresenta baixa capacidade de retenção de água, tendo drenagem rápida e eficiente (quanto maior sua proporção, mais rápida é a drenagem), levando ao estresse hídrico e proporcionando maior intensidade de compostos fenólicos.

Já as cumarinas e os açúcares redutores estão presentes em todos os tratamentos, sempre em baixa intensidade, ambos com média de 50\% (Tabela 2). A presença das cumarinas não foi citada em outros trabalhos para Moringa oleifera. Esta classe de metabólito é derivada da via do ácido chiquímico, formado pela condensação de dois metabólitos da glicose (fosfoenolpiruvato e eritrose-4-fosfato), após várias etapas metabólicas catalisadas pela radiação UV (TAIZ; ZEIGER, 2013). Como as plantas foram cultivadas em alta intensidade luminosa (região de estudo), isto poderia justificar a sua presença constante, embora outros trabalhos também tenham sido realizados em áreas tropicais. Da mesma forma, em relação aos açúcares redutores, os diferentes tipos de substratos não interferiram em sua produção e talvez seja necessária a variação de luminosidade para obtenção de diferentes intensidades.

Os alcaloides foram os metabólitos que apresentaram a menor intensidade $(7,1 \%)$, sendo encontrados apenas em plantas produzidas em substratos com a presença de húmus e em baixa intensidade. Desta maneira, poder-se-ia supor que é necessário um solo mais fértil para a produção destes compostos, o que pode ser confirmado pela análise dos nutrientes do solo (Tabela 1), que indicou que o vermicomposto 
aumentou a riqueza, em termos de íons. De acordo com Kasolo et al. (2011), as folhas de Moringa oleifera contêm alcaloides, que são compostos contendo nitrogênio, comumente utilizados com propriedades antimicrobianas devido a sua capacidade de se intercalar com DNA dos microrganismos. Esta ação poderia ser a responsável por parte de seu valor medicinal, embora o mecanismo de ação dos compostos seja pouco compreendido até o momento.

Os esteroides foram encontrados em todos os tratamentos, com intensidade média de $35,7 \%$, aparecendo em maior intensidade em T2, T4 e T6 (Tabela 2). De modo geral, os esteroides originados da via do ácido mevalônico são comuns nos vegetais e importantes componentes de membranas, por estabilizarem as caudas dos fosfolipídios, e possuem como característica especifica, atuação como reguladores de crescimento (TAIZ; ZEIGER, 2013). Não foi observado um padrão na intensidade deste componente, em que as maiores intensidades ocorreram na presença de vermicomposto (40\%), casca de arroz (40\%) e solo argiloso (40\%); ou seja, solos mais férteis e/ou sujeitos a estresse hídrico poderiam aumentar a intensidade dos esteroides nas plantas.

Já os heterosídeos cardioativos ocorreram em todos os tratamentos, com alta intensidade em T3, T4 e T5; média, T1 e T2 e, baixa intensidade, T6 e T7 (Tabela 2). Este é um grupo particular de heterosídeos, constituído por moléculas de açúcar ligadas à aglicona esteroidal. De acordo com a estrutura e propriedades do núcleo molecular que as compõe, é estudado com base nas suas propriedades físico-químicas e biológicas, que podem variar em termos de presença e de intensidade, fator muitas vezes relacionado a sua solubilidade em água e em solventes polares (metanol e etanol); por outro lado, são pouco solúveis ou insolúveis em meio que contenha solventes apolares, tais como o clorofórmio e o benzeno (RATES et al., 2017).

Outro fator a ser levado em consideração foi o solvente extrator; sabe-se que praticamente todos os constituintes de interesse para a análise fitoquímica apresentam alguma solubilidade em metanol, um solvente polar prótico, que tem uma maior afinidade por heterosídeos (poliglicosídeos), podendo também extrair mucilagens, goma e pectina, sais de alcaloides, flavonoides, catequinas, procianidinas e os açúcares. De modo geral, em plantas, por exemplo, solventes apolares são os mais indicados para a extração de óleos, pigmentos e esteroides (ZUANAZZI; MONTANHA, 2010). Desta maneira, o solvente e o método de extração utilizado podem ter influenciado na classe de metabólitos secundários encontrados, conforme relatado por Ayinde, Onwukaeme e Omogbai (2007) e Tijani et al. (2009).

A variabilidade encontrada na intensidade dos heterosídeos indica um padrão não muito claro, embora seja evidente que substratos com argila propiciaram a menor intensidade, enquanto os demais, média ou alta. A argila, talvez por apresentar maior capacidade de processos de compactação de solo, retenção de água e saturação hídrica, dificulte a produção deste metabólito, fator relacionado a uma maior dificuldade de absorção de íons do solo, restringindo o acesso aos nutrientes.

Por outro lado, a presença de heterosídeos cardioativos também foi relatada por Roopalatha e Nair (2013), com intensidade média em extrato etanólico, indicando que este metabólito é encontrado em outras condições de cultivo. Porém, este grupo de metabólito secundário deve ser visto com certa prudência para espécies vegetais empregadas na medicina popular e na alimentação, pois sua utilização por pessoas com insuficiência cardíaca poderia levar a graves danos, já que sua dose terapêutica é muito próxima à dose tóxica, causando intoxicação e provocando a morte por parada cardíaca (RATES et al., 2017).

Em relação ao crescimento da espécie em diferentes condições de cultivo, os resultados obtidos indicam que os substratos exercem influência sobre o desenvolvimento da espécie, quanto ao crescimento em altura e acúmulo de matéria seca foliar (Figura 1). O tratamento T2 apresentou o melhor resultado para ambos os parâmetros, enquanto T1 e T7, os piores. Em relação à diversidade de compostos por MSF, T2 e T3 se destacaram com 8 classes de metabólitos secundários, enquanto T5 apresentou a menor diversidade (6). 


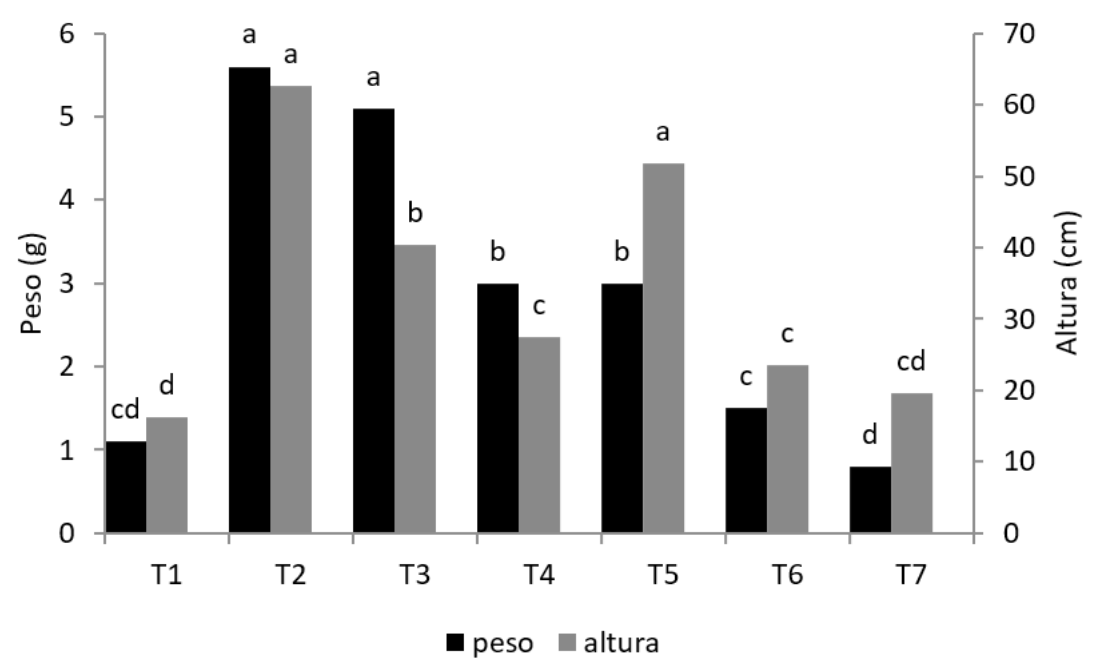

FIGURA 1: Crescimento em altura ( $\mathrm{cm}$ ) e massa seca foliar ( $\mathrm{g}$ ) de Moringa oleifera, aos 105 dias de plantio a pleno sol, Campo Grande, Mato Grosso do Sul. Letras iguais no mesmo tipo de coluna não diferem estatisticamente (5\% de probabilidade) pelo teste de Tukey.

FIGURE 1: Growth in height $(\mathrm{cm})$ and leaf dry mass (g) from Moringa oleifera at 105 days of cultivation in full sun, Campo Grande, Mato Grosso do Sul. Equal letters in the same column type do not differ statistically (5\% probability) by Tukey test.

Paulus et al. (2008) e Morais (2009) também indicaram que a concentração de nutrientes no solo ou na água, além de outros fatores ambientais, afetam a diversidade e a intensidade de metabólitos nas plantas.

O substrato T2 (NQ60 x 40VC) apresentou melhor crescimento $(62,7 \mathrm{~cm} \pm 3,2)$ e MSF $(5,6 \mathrm{~g} \pm$ 0,5); T3 (NQ80 x 20VC) também possui bom crescimento em altura $(40,3 \mathrm{~cm} \pm 2,2)$ e peso $(5,1 \mathrm{~g} \pm 1,0)$, indicando que uma maior presença de vermicomposto propicia melhor crescimento (Figura 1); além disto, as plântulas de ambos os tratamentos possuíam desenvolvimento mais homogêneo (menor desvio padrão).

Por outro lado, o substrato T5 (NQ80 x 20CAC), com crescimento de 51,8 $\mathrm{cm} \pm 13,9$ e peso de $3,0 \mathrm{~g} \pm 0,7$ (Figura 1), produziu plântulas mais irregulares, com crescimento desigual em todo o período de avaliação, fator evidenciado pelo maior desvio padrão.

Se o objetivo principal do cultivo da espécie for sua utilização em projetos paisagísticos, o tratamento T2, com maior proporção de vermicomposto, seria o melhor. Uma maior quantidade de húmus de minhoca como substrato, permite uma maior retenção de umidade e propicia melhor fertilidade, o que favorece o crescimento da planta e, baixa intensidade $(++)$ de compostos fenólicos, taninos, flavonoides e heterosídeos cardioativos.

Para a alimentação humana, como ocorre em algumas regiões, o recomendado é a utilização de substratos contendo argila, como no caso de T6 e T7, em que a produção de heterosídeos cardioativos foi a menor. Contudo, a produtividade das plantas é afetada e solos com $40 \%$ de argila foram melhores, caso de T6. Este também seria o melhor tratamento, levando-se em consideração o cultivo de uma espécie rica em compostos fenólicos, entre eles, flavonoides, para utilização humana. Os compostos fenólicos formam um grupo de substâncias presentes em folhas da espécie estudada e possuem propriedades antioxidantes, antiinflamatórias, antimicrobianas e anticarcinogênicas (ABE et al., 2007; VIZZOTTO; KROLOW; WEBER, 2010).

Os substratos contendo casca de arroz (T4 e T5) apresentaram como característica uma alta intensidade de heterosídeos cardioativos em suas folhas; os resultados também indicaram que a mudança na proporção da casca de arroz no substrato alterou a composição dos compostos fenólicos nas folhas, maior em T4 e, no crescimento, maior em T5. Para a produção de mudas visando ao paisagismo, T5 seria um substrato adequado, pois permitiu o segundo melhor crescimento, apesar da casca de arroz ser considerada um substrato que pode levar à deficiência de conservação de umidade homogênea, além de ser pobre em nutrientes (HERRERA; ECHAVARRÍA, 2009). 
Os fitoquímicos encontrados em Moringa oleifera são provavelmente os responsáveis em conferir amplo espectro de atividades biológicas atribuídas as suas folhas, sugerindo a importância da confirmação de sua presença. Por outro lado, o presente estudo sugere cautela no uso indiscriminado de suas folhas, uma vez que sua composição depende do meio em que a planta é cultivada, com a constatação da presença de compostos bioativos com diversas atividades farmacológicas.

\section{CONCLUSÕES}

A espécie Moringa oleifera, quando cultivada em diferentes substratos, apresentou alteração na composição química de extratos das folhas, com diferenças nos teores de compostos fenólicos, flavonoides e demais fitoconstituintes, além de afetar o crescimento em altura e acúmulo de biomassa foliar.

Se o objetivo principal for a utilização da espécie em projetos paisagísticos, o tratamento T2 seria o mais adequado; neste aspecto, T5 também se destaca. Porém, para alimentação humana e produção de compostos fenólicos e flavonoides, T6 é o mais o indicado.

\section{AGRADECIMENTOS}

À Coordenação de Aperfeiçoamento de Pessoal de Nível Superior (CAPES), pela bolsa de pósgraduação; ao Conselho Nacional de Desenvolvimento Científico e Tecnológico (CNPq), pelas bolsas de produtividade em pesquisa e à FUNADESP, pela bolsa de Iniciação Científica. Ao CNPq, INAU, CPP e FUNDECT, pelo apoio financeiro e também à Universidade Anhanguera-Uniderp, pelo financiamento do Grupo Interdisciplinar de Pesquisa (Projeto GIP).

\section{REFERÊNCIAS}

ABE, L. T. et al. Compostos fenólicos e capacidade antioxidante de cultivares de uvas Vitis labrusca L. e Vitis vinifera L. Ciência e Tecnologia de Alimentos, Campinas, v. 27, n. 2, p. 394-400, 2007.

ANWAR, F. et al. Moringa oleifera: a food plant with multiple medicinal uses. Phytotherapy Research, Reading, v. 21, n. 1, p. 17-25, 2007.

ATHAYDE, M. L. et al. Saponinas. In: SIMÕES, C. M. O. et al. Farmacognosia: do produto natural ao medicamento. Porto Alegre: Artmed, 2017. p. 285-303.

AYINDE, B. A.; ONWUKAEME, D. N.; OMOGBAI, E. K. Isolation and characterization of two phenolic compounds from the stem bark of Musanga cecropioides R. Brown (Moraceae). Acta Poloniae Pharmaceutica, Warszawie, v. 64, n. 2, p. 183-186, 2007.

BAMISHAIYE, E. I. et al. Proximate and phytochemical composition of Moringa oleifera leaves at three stages of maturation. Advanced Journal of Food Science and Technology, Karnataka, v. 3, n. 4, p. 233-237, 2011.

CARDOSO, M. G. et al. Metabólitos secundários vegetais: visão geral química e medicinal. Lavras: Universidade Federal de Lavras, 2001. 81 p.

CAPECHE, C. L. et al. Parâmetros técnicos relacionados ao manejo e conservação do solo, água e vegetação. Rio de Janeiro: Embrapa solos, 2004. (Comunicado Técnico, n. 28). 16 p.

CHUANG, P. H. et al. Anti-fungal activity of crude extracts and essential oil of Moringa oleifera Lam. Bioresource Technology, Mohali, v. 98, p. 232-236, 2007.

CLAESSEN, M. E. C. (Org.). Manual de métodos de análise de solo. 2. ed. Rio de Janeiro: Embrapa; CNPS, 1997. $212 \mathrm{p}$.

COSTA, L. C. B. et al. Efeito da adubação química e orgânica na produção de biomassa e óleo essencial em capim-limão [Cymbopogon citratus (DC.) Stapf.]. Revista Brasileira de Plantas Medicinais, Paulínia, v. 10, n. 1, p. 16-20, 2008.

DONAGEMA, G. K. et al. (Org.). Manual de métodos de análise de solos. 2. ed. Rio de Janeiro: Embrapa Solos, 2011. $230 \mathrm{p}$.

DUBEY, D. K. et al. A multipurpose tree - Moringa oleifera. International Journal of Pharmaceutical and Cemical Sciences, Índia, v. 2, n. 1, p. 415-423, 2013. 
FAHEY, J. W. Moringa oleifera: a review of the medical evidence for its nutritional, therapeutic, and prophylactic properties. Part 1. Trees for Life Journal, Wichita, v. 1, n. 5, p. 1-24, 2005.

FOIDL, N.; MAYORGA, L.; VÁSQUEZ, W. Utilización del marango (Moringa oleifera) como forraje fresco para ganado. Manágua: Universidad Nacional de Ingeniería, 2003. $10 \mathrm{p}$.

FONTOURA, F. M. et al. Seasonal effects and antifungal activity from bark chemical constituents of Sterculia apetala (Malvaceae) at Pantanal of Miranda, Mato Grosso do Sul, Brazil. Acta Amazonica, Manaus, v. 45, n. 3, p. 283-292, 2015.

GOBBO-NETO, L.; LOPES, N. P. Plantas medicinais: fatores de influência no conteúdo de metabólitos secundários. Química Nova, São Paulo, v. 30, n. 2, p. 374-381, 2007.

HERRERA, R. M. M.; ECHAVARRÍA, V. C. Caracterización y distribución celular del proceso de producción de forraje hidropônico. Tecnura, Bogotá, v. 13, n. 25, p. 163-173, 2009.

HARBORNE, A. J. Phytochemical methods: a guide to modern techniques of plant analysis. London: Chapman \& Hall, 1998. 302 p.

INSTITUTO NACIONAL DE METEOROLOGIA. Estações Automáticas - Gráficos. Radiação, $1 \mathrm{~m}$. 2014. Disponível em: <http://www.inmet.gov.br/portal/index.php?r=home/page\&page=rede_estacoes_ auto_graf $>$. Acesso em: 02 mar. 2015.

INSTITUTO NACIONAL DE PESQUISAS ESPACIAIS (Brasil). Centro de Previsão de Tempo e Estudos Climáticos. Arquivos do Laboratório de Meteorologia e Climatologia, vinculados ao CPTEC-INPE. Campo Grande: INPE, 2014.

KÄMPF, A. N. Produção comercial de plantas ornamentais. 2. ed. Guaíba: Agrolivros, 2005. 256 p.

KASOLO, J. N. et al. Phytochemicals and acute toxicity of Moringa oleifera roots in mice. Journal of Pharmacognosy and Phytotherapy, Calcuta, v. 3, n. 3, p. 38-42, 2011.

MARIOT, M. P.; BARBIERI, R. L. Metabólitos secundários e propriedades medicinais da espinheira-santa (Maytenus ilicifolia Mart. ex Reiss. e M. aquifolium Mart.). Revista Brasileira de Plantas Medicinais, Paulínia, v. 9, n. 3, p. 89-99, 2007.

MATOS, F. J. A. Introdução a fitoquímica experimental. 3. ed. Fortaleza: Edições UFC, 2009. 150 p. MELO, S. S. N. S. Valor nutritivo de fenos de moringa (Moringa oleifera Lam) com diferentes idades de corte. 2012. 60 f. Dissertação Mestrado (Produção Animal) - Universidade Federal do Rio Grande do Norte, Macaíba, 2012.

MORAIS, L. A. S. Influência dos fatores abióticos na composição química dos óleos essenciais. Horticultura Brasileira, Brasília, v. 27, n. 2, p. 4050-4063, 2009.

MORELLI, M. R. S. Guia de produção para plantas medicinais, aromáticas e flores comestíveis. Porto Alegre: Cidadela Editorial, 2010. 252 p.

OLIVEIRA, A. K. M. et al. Leaf extract effects of Vochysia divergens on lettuce and tomato. Allelopathy Journal, Haryana, v. 31, n. 1, p. 129-138, 2013.

PARROTTA, J. A. Moringa oleifera Lam., 1785. In: ROLOFF, A. et al. (Ed.). Enzyklopädie der Holzgewächse, Handbuch und Atlas der Dendrologie. Weinheim: Wiley-VCH Verlag GmbH \& Co., 2009. p. 1-8.

PAULUS, D. et al. Solução nutritiva para produção de menta em hidroponia. Horticultura Brasileira, Brasília, v. 26, n. 1, p. 61-67, 2008.

PEGORARO, R. L. et al. Produção de óleos essenciais em plantas de Mentha x piperita L. var. piperita (Lamiaceae) submetidas a diferentes níveis de luz e nutrição do substrato. Revista Brasileira Botânica, São Paulo, v. 33, n. 4, p. 631-637, 2010.

PEIXOTO SOBRINHO, T. J. S. et al. Validação de metodologia espectrofotométrica para quantificação dos flavonoides de Bauhinia cheilantha (Bongard) Steudel. Revista Brasileira de Ciências Farmacêuticas, São Paulo, v. 44, n. 4, p. 683-689, 2008.

PHIRI, C.; MBEWE, D. N. Influence of Moringa oleifera leaf extracts on germination and seedling survival of three common legumes. International Journal of Agriculture and Biology, Beijing, v. 12, n. 2, p. 315-317, 2010.

RATES, S. M. K. et al. Heterosídeos cardioativos. In: SIMÕES, C. M. O. et al. Farmacognosia: do produto natural ao medicamento. Porto Alegre: Artmed, 2017. p. 272-284.

RODRIGUES, L. A. et al. Quality of Moringa oleifera Lam. seedlings cultivated in substrates with green 
coconut fiber and organic compounds. Revista Ceres, Viçosa, MG, v. 63, n. 4, p. 545-552, 2016.

ROOPALATHA, U. C.; NAIR, V. M. Phytochemical analysis of successive reextracts of the leaves of Moringa oleifera Lam. International Journal of Pharmacy and Pharmaceutical Sciences, Sagar, v. 5, n. 3, p. 629-634, 2013.

SAIDELLES, F. L. F. et al. Casca de arroz carbonizada como substrato para produção de mudas de tamboril-da-mata e garapeira. Semina: Ciências Agrárias, Londrina, v. 30, supl 1, p. 1173-1186, 2009.

SANTANA, C. R. et al. Caracterização físico-química da moringa (Moringa oleifera Lam.). Revista Brasileira de Produtos Agroindustriais, Campina Grande, v. 12, n. 1, p. 55-60, 2010.

SILVA JUNIOR, A. A. Epagri estuda a moringa, planta rica em vitaminas e minerais. Agropecuária Catarinense, Florianópolis, v. 26, n. 1, p. 5-5, 2013.

SOUSA, C. M. M. et al. Fenóis totais e atividade antioxidante de cinco plantas medicinais. Química Nova, São Paulo, v. 30, n. 2, p. 351-355, 2007.

TAIZ, L.; ZEIGER, E. Fisiologia vegetal. 5. ed. Porto Alegre: Artmed, 2013. 918 p.

TEDESCO, M. J. et al. Análise de solo, plantas e outros materiais. 2. ed. Porto Alegre: Universidade Federal do Rio Grande do Sul, 1995. 174 p.

TIJANI, A. Y. et al. Antidiarrhoeal and antibacterial properties of crude aqueous stem bark extract and fractions of Parkia biglobosa (Jacq) R. Br. Ex G. Don. African Journal of Pharmacy and Pharmacology, Africa, v. 3, n. 7, p. 347-353, 2009.

TORRES-CASTILLO, J. A. et al. Moringa oleifera: phytochemical detection, antioxidants, enzymes and antifugal properties. International Journal of Experimental Botany, Lancaster, v. 82, p. 193-202, 2013. VIZZOTTO, M.; KROLOW, A. C.; WEBER, G. E. B. Metabólitos secundários encontrados em plantas e sua importância. Pelotas: Embrapa Clima Temperado, 2010. 16 p.

ZUANAZZI, J. A.; MONTANHA, J. A. Flavonóides. In: SIMÕES, C. M. O. et al. Farmacognosia: da planta ao medicamento. Porto Alegre; Florianópolis: Editora UFRGS; UFSC, 2010. p. 577-614.

WAGNER, H.; BLADT, S. Plant drug analysis: a thin layer chromatography atlas. 2. ed. London: Springer, 2009. $384 \mathrm{p}$

WILLIAMS, R. J.; SPENCER, J. P.; RICE-EVANS, C. Flavonoids: antioxidants or signalling molecules? Free Radical Biology Medicine, Los Angeles, v. 36, n. 7, p. 838-849, 2004.

WINK, M. Evolution of secondary metabolites from an ecological and molecular phylogenetic perspective. Phytochemistry, London, v. 64, n. 1, p. 3-19, 2003. 